\title{
Altenpflege
}

Vorsprung durch Wissen

\section{DOSSIER 10}

\section{Neue Pflegegrade}

Die Pflegebegutachtung ab 2017:

So sind Sie auf die Umstellung optimal vorbereitet

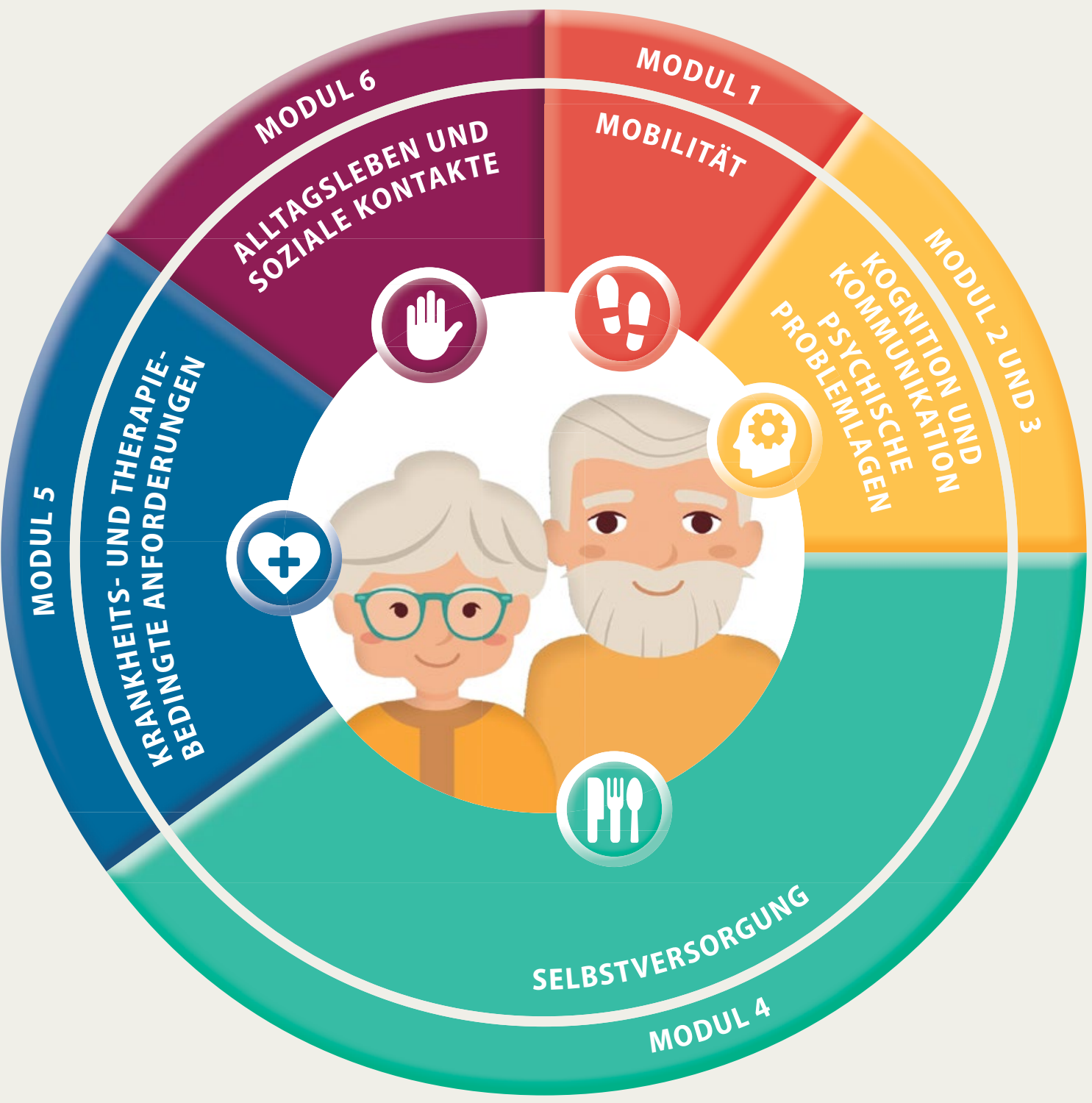



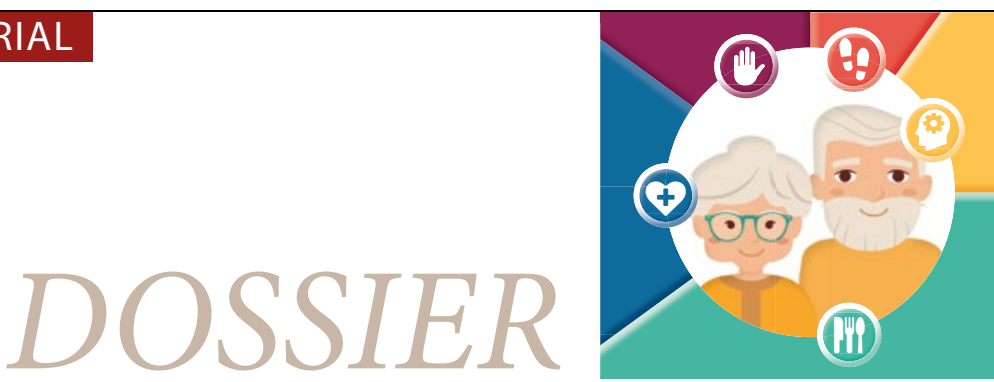

Neue Pflegegrade

\section{Die Perspektive wechseln}

Der neue Pflegebedürftigkeitsbegriff, der zum 1. Januar 2017 in der Pflegeversicherung eingeführt wurde, ist Teil eines in dieser Größenordnung noch nie dagewesenen Reformprozesses in der Pflege. Er bringt viele Veränderungen mit sich, die Sie, liebe Leserinnen und Leser, zu meistern haben. So hat er einerseits zum Ziel, die Bedürfnisse von Menschen mit Demenz ebenso zu berücksichtigen, wie die Bedürfnisse von Menschen mit körperlichen Einschränkungen. Andererseits soll nicht mehr der Hilfebedarf in Minuten, sondern der Grad der Selbstständigkeit und der vorhandenen Fähigkeiten eines Menschen Maßstab für seine Pflegebedürftigkeit sein. Es geht also um einen Perspektivwechsel in der Pflege. Mit dem Dossier möchten wir Sie dabei unterstützen, diesen Wechsel vorzunehmen und „Pflege neu zu denken“, wie es Annegret Miller ausdrückt, die Ihnen in ihrem Beitrag auf Seite 6 erläutert, wie das gelingt.

\section{Das neue Begutachtungsinstrument} ist das Handwerkszeug zur Umsetzung dieses Perspektivwechsels, da mit dem neuen Pflegebedürftigkeitsbegriff ein neues Verfahren zur Feststellung der Pflegebedürftigkeit verbunden ist. Dieses Instrument stellt den Menschen, seine Ressourcen und Fähigkeiten in den Mittelpunkt. Es fragt danach, wie sei-

\section{facebook.}

Diskutieren Sie

mit uns auch unter www.facebook.com/ altenpflege.vincentz ne Selbstständigkeit erhalten und gestärkt werden kann. Von dieser Selbstständigkeit hängt letztlich der ermittelte Pflegegrad ab - und damit von der Mobilität, da sie der Dreh- und Angelpunkt für die selbstständige Lebensweise einer pflegebedürftigen Person ist. Wie Sie die Fähigkeit zur Bewegung fördern und erhalten können, zeigt Ihnen Sabine Hindrichs in ihrem Beitrag auf Seite 16.
Die ermittelten Pflegegrade sind das Ergebnis eines komplexen Verfahrens mit Modulen und Gewichtungen. Entsprechend kommt es darauf an, das Einstufungsmanagement sehr sorgfältig durchzuführen, damit es nicht zu Fehleinstufungen kommt. Dass hier schon kleine Fehler eine große Wirkung haben können, lesen Sie im Beitrag von Nicole Franke auf Seite 22, die Ihnen auch sagt, wie Sie diese Fehler vermeiden. Und Bruno Ristok beschreibt ab Seite 28, warum es unter den Bedingungen des Strukturmodells so wichtig ist, das neue Begutachtungsinstrument regelmäßig intern einzusetzen.

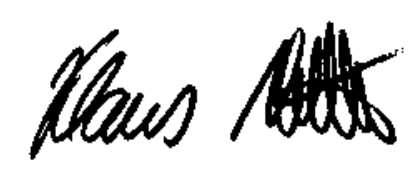

\section{Klaus Nolte}

Redakteur, Politikwissenschaftler M.A.

klaus.nolte@vincentz.net

T 0511 9910-122

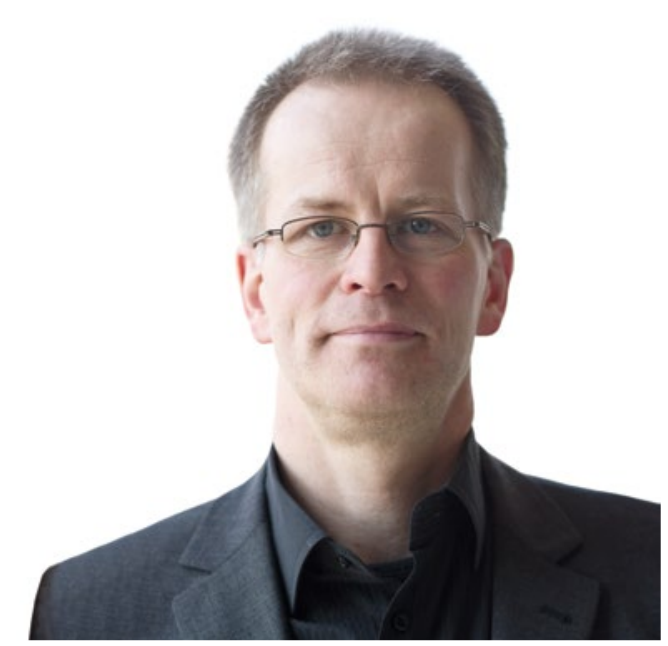

